\title{
Multiple high activity cysteine proteases of Leishmania mexicana are encoded by the Imcpb gene array
}

\author{
Colin D. Robertsont and Graham H. Coombs \\ Author for correspondence: Colin D. Robertson. Tel: +4441339 8855. Fax: +44 413305603.
}

Laboratory for Biochemical Parasitology, Department of Zoology, University of Glasgow, Glasgow G12 8QQ, UK

\begin{abstract}
The interrelationship of the multiple cysteine proteases (CPs) found characteristically at high activity in Leishmania mexicana amastigotes has been investigated. The mature forms of the five enzymes of groups B and C, which have subtly different substrate preferences, are the same size. Enzymically deglycosylated group A CP proteins also have the same molecular mass. Proteases of all three groups are specifically recognized by antisera raised against the group B or group C CPs. In addition, CPs of groups A, B and C have highly similar $\mathbf{N}$-terminal amino acid sequences. The consensus sequence matches that predicted from the sequenced Imcpb gene, which occurs in a tandem array of over ten similar genes. Thus, the results are consistent with the groups A, B and C CPs being products of different Imcpb genes within the array, the different genes encoding $\mathrm{CPs}$ with identical $\mathbf{N}$-termini, but with limited amino acid substitutions within the mature enzyme accounting for the different properties of the CPs. Evidence is also presented to indicate membrane-association of proteolytically active but less processed forms of Imcpb products.
\end{abstract}

Keywords: Leishmania mexicana, cysteine proteases, $\operatorname{lm} c p b$ genes, amino acid sequence

\section{INTRODUCTION}

The intracellular amastigote form of the protozoan parasite Leishmania mexicana has a much greater cysteine protease (CP) activity than promastigote forms (North \& Coombs, 1981; Coombs, 1982; Lockwood et al., 1987; Coombs et al., 1991; Robertson \& Coombs, 1992). It has been proposed that this high CP activity is crucially important for the survival of the amastigote in its host mammalian macrophage, and, hence, that the enzymes may be targets for novel anti-leishmanial drugs based on specific enzyme inhibitors or pro-drugs preferentially activable by the amastigote CPs.

Previous studies employing substrate-SDS-PAGE have

\footnotetext{
†Present address: Department of Veterinary Parasitology, University of Glasgow, Glasgow G61 1RQ, UK

Abbreviations: BCIP, 5-bromo-4-chloro-3-indolyl phosphate; BzFVRAMC, N-benzoyl-phenylalanyl-valyl-arginyl-7-amido-4-methylcoumarin; BzPFRpNA， N-benzoyl-prolyl-phenylalanyl-arginyl-para-nitroanilide; $C P$, cysteine protease; LVY-AMC, H-leucyl-valyl-tyrosyl-7-amido-4-methylcoumarin; NBT, nitro blue tetrazolium; PDA, piperazine diacrylamide; PFRAMC, H-prolyl-phenylalanyl-arginyl-7-amido-4-methylcoumarin; PVDF, polvinylidene difluoride; SUCAFK-AMC, $N$-succinyl-alanyl-phenylalanyllysyl-7-amido-4-methylcoumarin.
}

indicated that the high amastigote CP activity is due to multiple enzymes (North \& Coombs, 1981; Lockwood et al., 1987; Coombs et al., 1991; Robertson \& Coombs, 1990, 1992). The enzymes have been segregated into three groups, A, B and C, on the basis of their physical properties and substrate preferences (Robertson \& Coombs, 1990). The group A CPs are glycosylated as shown by their specific association with concanavalin A Sepharose, whereas the groups B and C CPs do not bind to the immobilized lectin. The groups B and C CPs differ in terms of their net charge at $\mathrm{pH} 6.0$ (the group $\mathrm{B}$ enzymes elute from anion-exchange columns at lower salt concentrations), and also in terms of their substrate preferences, with the group C CPs being less able to accommodate the bulky amino acid tyrosine in the substrate $\mathrm{P}_{\mathbf{1}}$ position.

The interrelationship of these enzymes was, however, uncertain, and it was not apparent whether the enzymes are encoded by different genes or are post-transcriptionally or post-translationally modified forms of just one gene product. It is known, for example, that differential proteolytic processing at the $\mathrm{N}$-terminus of the mature enzyme of a barley aleurone layer CP is responsible for multiple CP activities detected using substrate-SDS- 
PAGE gels (Koehler \& Ho, 1988). This investigation was undertaken with the aim of resolving this uncertainty.

Two CP genes have been cloned from a $L$. mexicana amastigote cDNA library and sequenced (Mottram et al., 1992; Souza et al., 1992). One of these, Imcpa, is a singlecopy gene, and, although it is expressed at higher levels in amastigotes than in multiplicative promastigotes, it does not appear to encode any of the multiple high-activity CPs of the amastigote (Mottram et al., 1992). The other gene, $\operatorname{lm} c p b$, is present as a tandem array of more than ten copies. Its mRNA is much more abundant in amastigotes than promastigotes (Souza et al., 1992), indicating a transcriptional regulation that parallels the expression of the multiple CP activities.

Here we report evidence, including $\mathrm{N}$-terminal sequence data, which indicates that the multiple high-activity CPs of L. mexicana amastigotes are products of the $l m c p b$ gene array, and supports the notion that expression of slightly different copies of $l m c p b$ within the gene array accounts for the different CP activities detected. In addition, data are presented to show that other similar CP activities are membrane-associated.

\section{METHODS}

Parasites. Promastigotes of L. mexicana (MNYC/BZ/62/ M379) were grown axenically in vitro at $25^{\circ} \mathrm{C}$ as described previously (Mallinson \& Coombs, 1986). Multiplicative promastigote populations were harvested $2 \mathrm{~d}$ after culture initiation at $10^{5}$ parasites $\mathrm{ml}^{-1}$, and stationary-phase populations (containing putative metacyclic promastigotes) were harvested $9 \mathrm{~d}$ after culture initiation. The parasites were harvested and washed as described previously (Mallinson \& Coombs, 1986).

Amastigotes of $L$. mexicana were purified essentially as described previously (Mottram \& Coombs, 1985) from cutaneous lesions raised in CBA mice.

Purified parasites were stored as washed pellets at $-70{ }^{\circ} \mathrm{C}$ until required.

CP purification. CPs of groups A, B and C were purified from L. mexicana amastigotes using the chromatography procedures and enzyme assays described previously (Robertson \& Coombs, 1990). Briefly, the supernatant fraction $(11600 \mathrm{~g}, 5 \mathrm{~min})$ of an amastigote lysate prepared in $0.25 \mathrm{M}$ sucrose $/ 0.25 \%(\mathrm{v} / \mathrm{v})$ Triton X-100 was passed through a Pharmacia HR 10/30 Superose 12 gel-filtration column. Fractions with activity towards BzPFR $p$ NA were pooled and applied to a Pharmacia Mono Q HR 5/5 column and eluted with a non-linear $\mathrm{NaCl}$ gradient. After gelatin-SDS-PAGE analysis of the eluted activities, fractions having $\mathrm{CP}$ activities of groups $\mathrm{A}$ and $\mathrm{B}$, groups $A, B$ and $C$, and groups $A$ and $C$, were pooled separately. These were then passed through a $1 \mathrm{ml}$ column of concanavalin A Sepharose to which the group A CPs bound specifically. The three separate pools containing CPs of groups A, B and C, respectively, were concentrated by ultrafiltration on an Amicon PM-10 filter and passed through a Pharmacia Superdex 75 HR $10 / 30$ gel-filtration column at $0.5 \mathrm{ml} \mathrm{min}^{-1}$ in $10 \mathrm{mM}$ sodium phosphate buffer, $\mathrm{pH} \mathrm{6.0.} \mathrm{Fractions} \mathrm{having} \mathrm{activity} \mathrm{towards}$ BzPFR $p$ NA were pooled and concentrated, and represent the purified $C P$ pools used in this study.

The pellet fraction obtained from the amastigotes lysate was washed twice with $0 \cdot 1 \mathrm{M}$ sodium phosphate buffer, $\mathrm{pH} 6 \cdot 0$, and stored at $-20{ }^{\circ} \mathrm{C}$ resuspended in a small volume of the same buffer. This material represents the crude preparation of group E CPs. Experiments to solubilize the group E CP activity used a fraction of this crude preparation, pelleted by centrifugation $(11600 \mathrm{~g}, 5 \mathrm{~min})$ and washed twice with storage resuspension buffer. The pellet was then resuspended with solubilization buffer.

SDSPAGE. Mini $(0.75 \mathrm{~mm}$ thickness) $11 \%(\mathrm{w} / \mathrm{v})$ acrylamide SDS-PAGE gels were used for protein analyses and for protein separation prior to Western blotting. Analysis of CP activity towards both copolymerized gelatin and flurogenic peptide substrates after SDS-PAGE was done as described previously (Robertson \& Coombs, 1990).

The following modifications were used for SDS-PAGE separation of $\mathrm{CP}$ proteins for sequence analysis. The gels were prepared with PDA (Bio-Rad) substituted weight for weight with $N, N^{\prime}$-methylene-bisacrylamide. This did not significantly alter the mobilities of the proteins in the gels. Prior to loading the sample, the gel was run for 60 min at $3 \mathrm{~mA}$ with $0.05 \mathrm{mM}$ reduced glutathione in the cathode buffer. The sample was separated with fresh electrophoresis buffer, with $0 \cdot 1 \mathrm{mM}$ sodium thioglycolate included in the cathode buffer.

$\mathbf{N}$-terminal sequence analysis. Purified proteins for sequencing were separated by SDS-PAGE as described above, and electroblotted to Problott PVDF membrane (Applied Biosystems) for $30 \mathrm{~min}$ at $50 \mathrm{~V}$ in $10 \mathrm{mM}$ CAPS/ $\mathrm{NaOH} \mathrm{pH} 11,10 \%(\mathrm{v} / \mathrm{v})$ methanol. The blotted proteins were stained on the membrane with Amido black and excised for sequence analysis (Matsudaira, 1987). Sequencing was performed by Mr B. Dunbar at the SERC Protein Sequencing Facility, Department of Molecular and Cell Biology, University of Aberdeen, UK.

Production of antisera. Antisera against group B CP proteins (anti-B CP antiserum) and against group C CP proteins (anti-C CP antiserum) were produced in New Zealand White rabbits following standard procedures (Harlow \& Lane, 1988). Reduced and denatured CP proteins (approx. $10 \mu \mathrm{g}$ for each group) were excised from SDS-PAGE gels and homogenized with Freund's complete adjuvant for the first inoculation, and Freund's incomplete adjuvant for subsequent boosts. Antisera were collected on day 10 after the third boost.

Immunostaining of Western blots. SDS-PAGE gels were blotted to $0 \cdot 22 \mu \mathrm{m}$ nitrocellulose in $25 \mathrm{mM}$ Tris $/ 192 \mathrm{mM}$ glycine $/ 20 \%$ (v/v) methanol for $60 \mathrm{~min}$ at $100 \mathrm{~V}$ (Bio-Rad mini-transblotter). The blots were routinely stained with Ponceau S to allow molecular mass standard (Sigma MW SDS$70 \mathrm{~L}$ ) positions to be marked. The blots were blocked overnight at $4{ }^{\circ} \mathrm{C}$ in $25 \mathrm{mM}$ Tris $/ 0.15 \mathrm{M} \mathrm{NaCl} / 2.7 \mathrm{mM} \mathrm{KCl} 0.02 \%$ Tween 20 , pH 7.5 (TBS-Tween), containing $5 \%(\mathrm{w} / \mathrm{v})$ non-fat dried milk and $10 \%(\mathrm{v} / \mathrm{v})$ horse serum, and then incubated in the same solution for $2 \mathrm{~h}$ at $4{ }^{\circ} \mathrm{C}$ with $1 / 500$ anti-B CP antiserum or $1 / 1000$ anti-C CP antiserum. The blots were washed three times with TBS-Tween and once with $50 \mathrm{mM}$ Tris $/ 0.15 \mathrm{M} \mathrm{NaCl}$, $\mathrm{pH} 7.4$ (Tris- $\mathrm{NaCl}$ ), before being incubated at ambient temperature for $60 \mathrm{~min}$ in Tris- $\mathrm{NaCl}$ containing $5 \%(\mathrm{w} / \mathrm{v})$ non-fat dried milk and $1 / 7500$ goat anti-rabbit $\operatorname{IgG}(\mathrm{Fc})$ alkaline phosphatase conjugate (Promega). The blots were then washed with four changes of Tris- $\mathrm{NaCl}$ and incubated in alkaline phosphatase assay buffer $(0.1 \mathrm{M}$ Tris $/ 0.1 \mathrm{M} \mathrm{NaCl} / 5 \mathrm{mM}$ $\mathrm{MgCl}_{2} / 0.9 \mathrm{mM} \mathrm{BCIP} / 0.2 \mathrm{mM}$ NBT, $\mathrm{pH}$ 9.5) until stained, and the reaction stopped in $0.5 \mathrm{M}$ EDTA $/ \mathrm{NaOH}, \mathrm{pH} 8$.

Enzymic $\boldsymbol{N}$-deglycosylation. Samples of purified CPs $(0.02 \mathrm{ml})$ were made $1 \%(\mathrm{w} / \mathrm{v})$ with respect to SDS and incubated at $100{ }^{\circ} \mathrm{C}$ for $2 \mathrm{~min}$. The samples were mixed with $0.18 \mathrm{ml} 0.55 \%$ (w/v) n-octylglucoside in $20 \mathrm{mM}$ sodium phosphate $/ 10 \mathrm{mM}$ $\mathrm{NaN}_{3} / 50 \mathrm{mM}$ EDTA, $\mathrm{pH} 7 \cdot 2$, and again incubated for $2 \mathrm{~min}$ at $100^{\circ} \mathrm{C}$. The sample was split in two, and $2 \mu \mathrm{l}$ of stock 
Flavobacterium meningosepticum $N$-glycosidase $F$ (Boehringer Mannheim) was mixed with one aliquot. Both samples were incubated for $24 \mathrm{~h}$ at $37^{\circ} \mathrm{C}$, then concentrated by centrifugal evaporation at ambient temperature to about $25 \mu \mathrm{l}$, mixed with an equal volume of reducing SDS-PAGE sample buffer, and incubated for $3 \mathrm{~min}$ at $100^{\circ} \mathrm{C}$ before analysis.

\section{RESULTS}

\section{Purification of groups A, B and C CPs}

The procedures used to purify the L. mexicana amastigote CPs of groups $\mathrm{A}, \mathrm{B}$ and $\mathrm{C}$ do not result in individual activities, but in groups of CPs free from other proteins (Robertson \& Coombs, 1990). Purified CPs of groups A, $B$ and $C$ were prepared as described in Methods, and are shown silver-stained in Fig. 1. Of particular interest is the observation that when reduced and denatured, the $\mathrm{CP}$

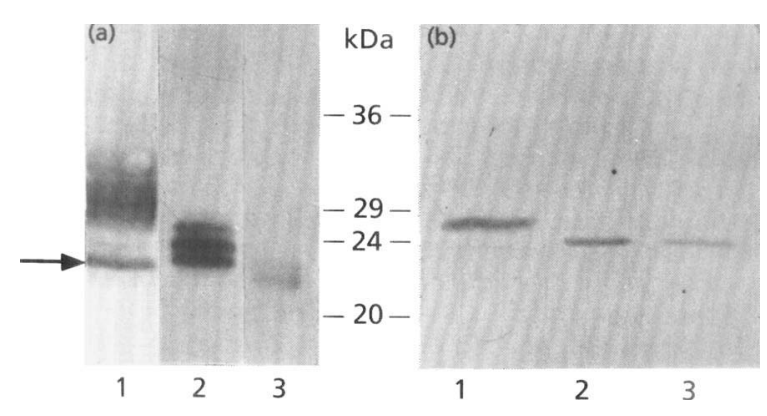

Fig. 1. Silver staining after SDS-PAGE of groups $A, B$ and $C$ CPs. Samples of group A (lanes 1), group B (lanes 2) and group $C$ (lanes 3) CP preparations were run in SDS-PAGE gels and silver stained. The samples in panel a are partially denatured and not reduced (as for protease activity analysis), whereas those in panel $b$ are fully reduced and denatured. Note that the group A CP preparation had some contaminating proteins (arrowed in lane 1, panel a; see also Fig. 5), and that different loadings and staining times were used for the different gels.

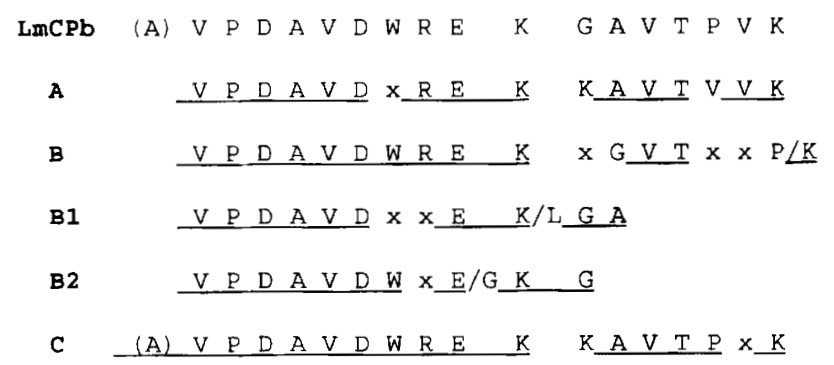

Fig. 2. Comparison of $\mathrm{N}$-terminal amino acid sequences of $L$. mexicana groups $A, B$ and $C$ CPs with that predicted from the $I m c p b$ gene. The amino acid sequence predicted from the Imcpb gene (Souza et al., 1992) is compared with the amino acid sequences determined for the $\mathrm{N}$-terminus of preparations of different $L$. mexicana CPs. Residues exactly matching those predicted from the gene sequence are underlined. Sequencing cycles which did not suggest an amino acid are indicated by $x$. Where more than one amino acid was found, the alternatives are given. The sequence determined for the C CP preparation suggested overlapping sequences, one of which started with an additional alanine residue. proteins of each of the three groups run together in SDSPAGE gels as single bands with lower mobility than the multiple bands observed using non-reduced, partially denatured samples.

\section{Comparison of $\mathrm{N}$-terminal amino acid sequences}

At present, electrophoresis is the only way to separate the individual activities of each group of CPs. To investigate whether N-terminal heterogeneity occurred between the multiple enzymes (as with the barley aleurone layer CPs: Koehler \& Ho, 1988), the CP proteins were separated by SDS-PAGE, and blotted to a PVDF membrane from which individual bands could be excised for sequencing (Matsudaira, 1987). To minimize the risk of blocking the N-terminus of the CPs during electrophoresis, reducing agents, as polymerization radical scavengers, were included in the electrophoresis cathode buffer during both the electrophoretic separation and a pre-run of the gel without sample. As a result of the pre-run, the $\mathrm{pH}$ discontinuity between the stacking and resolving phases of the gel was lost, and so too was the separation of the individual proteins of each group of CPs. Indeed, under such conditions, the CP proteins seem to behave as their reduced and denatured forms. Thus, it was only possible to obtain N-terminal sequences for the reduced and denatured pools of purified CPs containing, respectively, several group $A$, three group $B$ and two group $C \mathrm{CP}$ proteins (Fig. 2). By taking the risk that the proteins might become $\mathrm{N}$-terminally blocked, sequence data were obtained for homogeneous preparations of CPs B1 and B2 (Robertson \& Coombs, 1990), purified by excision of bands of activity towards PFR-AMC after separation of the purified group B CPs by SDS-PAGE (Fig. 2). (The fragments of excised gel having the single $\mathrm{CP}$ activity were incubated at $100^{\circ} \mathrm{C}$ in reducing SDS-PAGE sample buffer and electrophoresed in an SDS-PAGE gel prepared for sequencing proteins.) In all but one of the cases, the sequence was identical for the first ten amino acids, and matches exactly that predicted for the same N-terminal region of the mature $l m c p b$ product (Souza et al., 1992). One of the $C$ proteins had an additional alanine residue at the $\mathrm{N}$-terminus and this was also predicted by $\operatorname{lmc} p b$. The amino acid sequences subsequent to residue 10 were also very similar, although some differences were apparent.

\section{Western blot analysis of $L$. mexicana lysates and CP groups}

Antisera were raised in rabbits against the reduced and denatured group B and group C CP proteins. Both antisera recognized the same molecules in Western blots of crude L. mexicana amastigote lysates. Fig. 3 shows the data with anti-C CP antiserum; anti-B CP antiserum gave identical results. The predominant molecule recognized was the reduced and denatured form of the groups B and C CP proteins. This is consistent with results from substrate-SDS-PAGE gels that show these to be the most abundant activities (Robertson \& Coombs, 1990). A molecule of the same apparent molecular mass was also recognized in lysates prepared from stationary-phase 

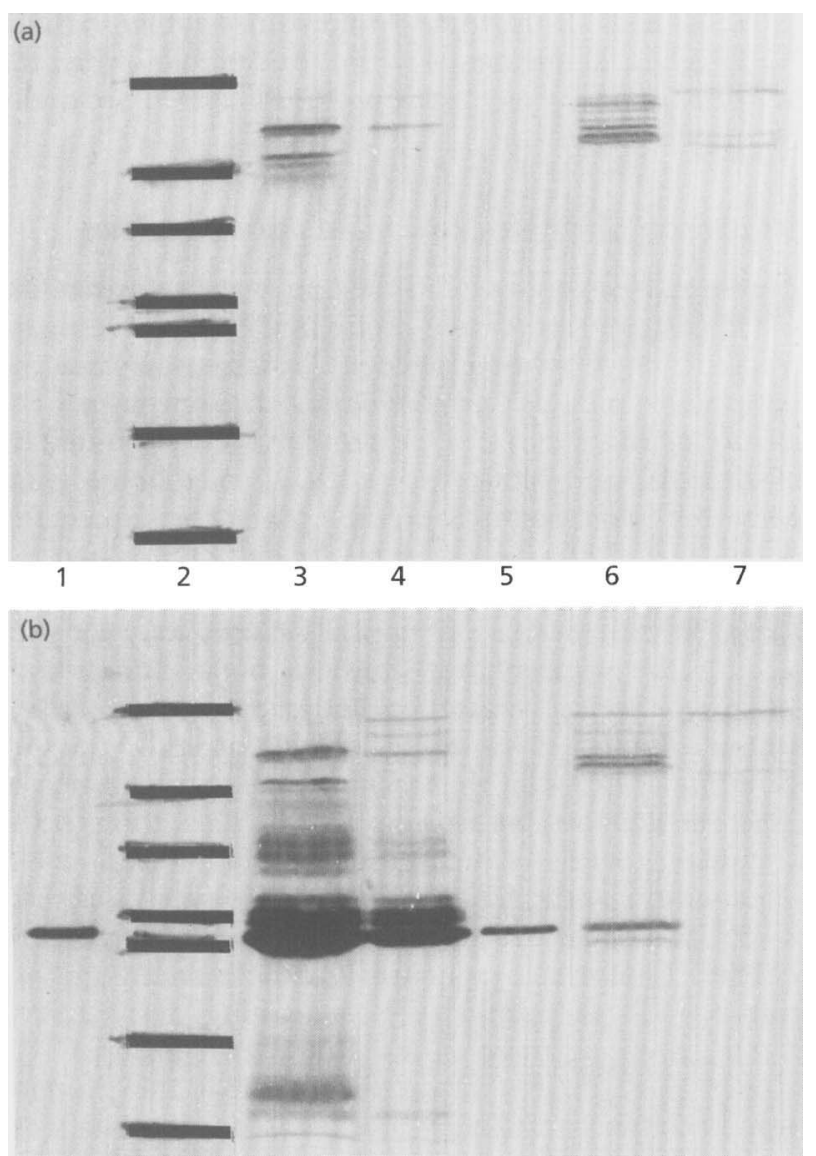

Fig. 3. Western blots of $L$. mexicana lysates probed with anti- $C$ $C P$ antiserum. Reduced and denatured crude lysates of $L$. mexicana amastigotes (lanes 3-5; lane 3, $30 \mu \mathrm{g}$ protein; lane 4, $6.5 \mu \mathrm{g}$ protein; lane $5,0.3 \mu \mathrm{g}$ protein), stationary-phase promastigotes (lane $6,30 \mu \mathrm{g}$ protein) and exponential-phase promastigotes (lane $7,30 \mu \mathrm{g}$ protein) were probed on Western blots with anti-C CP antiserum (panel b). Lane 1 has reduced and denatured purified group B CP protein, and lane 2 molecular mass markers $(66,45,36,29,24,20$ and $14 \mathrm{kDa}$; bars have been drawn over the pencil marks on the original blots). Lanes 3, 6 and 7 have the same protein load, and lanes 4, 6 and 7 have material derived from the same number of parasites $\left(5.6 \times 10^{6}\right)$. Panel a was probed in parallel with pre-immune serum.

promastigote populations. Again, this is consistent with the presence of groups B and C CP activities in such parasite populations (Robertson \& Coombs, 1992). A molecule of lower apparent molecular mass was also recognized in this sample, and seems to be absent from amastigotes. It is possible that this protein represents the reduced and denatured form of the metacyclic promastigote-specific group F CPs (Robertson \& Coombs, 1992).

The reduced and denatured group A CPs were also recognized by these antisera (Fig. 4), again indicating a close similarity between the groups A, B and C CPs. The group A CPs were recognized, even after enzymic deglycosylation by $N$-glycosidase $F$. The enzymic deglycosylation shows that the group A CPs are $N$ -

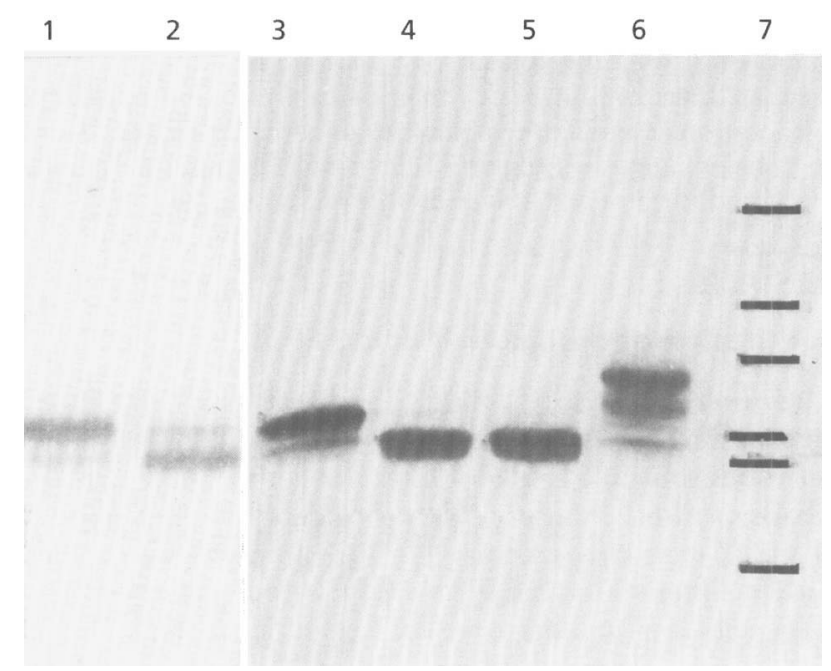

Fig. 4. Western blot of $L$. mexicana $C P$ groups probed with anti-C CP antiserum. Reduced and denatured samples of purified L. mexicana CP groups A (lanes 1-3), B (lane 4) and C (lane 5) were probed on Western blots with anti-C CP antiserum. The group A CP proteins in lane 2 had been treated with $\mathrm{N}$-glycosidase $\mathrm{F}$, and the sample in lane 1 is the negative control for this experiment. Lane 6 has the reduced and denatured pellet fraction of a $L$. mexicana amastigote lysate that contained group E CP activity. The positions of molecular mass markers $(66,45,36,29,24$ and $20 \mathrm{kDa}$; bars have been drawn over the pencil marks on the original blot) are shown in lane 7. Note that the group A preparation has some groups B and C CP proteins (lane 3 and Fig. 1), and that the amastigote lysate pellet fraction retains low levels of the groups A, B and C CP proteins (lane 6). A parallel blot was probed with preimmune serum as a control; no bands were visible.

glycosylated, and that the carbohydrate-free group A CP proteins have a similar molecular mass as the groups $B$ and C CPs. The latter enzymes, and the group E CP proteins (see below), were unaltered by $N$-glycosidase $\mathrm{F}$ treatment (data not shown), indicating that they are not $N$-glycosylated.

\section{Characteristics of group E CPs}

Two further molecules in the amastigote lysate specifically recognized by both antisera appear to belong to a group of $C P_{s}$ that we have designated group $E$. These molecules have molecular masses of $36.3 \mathrm{kDa}$ and $32.5 \mathrm{kDa}$, and have the peculiarity that they are found associated with the pellet fraction after centrifugation of amastigote lysates prepared by repeated cycles of freezing and thawing or in $0.25 \%(\mathrm{v} / \mathrm{v})$ Triton X-100 detergent. Such a pellet fraction has two distinct activities with lower mobilities than the groups A, B or C CPs in gelatin-SDSPAGE gels (Fig. 5). These activities (group E CPs) are released from the lysate pellet fraction by $0.1 \%(\mathrm{w} / \mathrm{v})$ SDS (hence they are solubilized by SDS-PAGE sample buffer, and run in the gels), $2 \mathrm{M} \mathrm{NaCl}$ and high $\mathrm{pH}$. The $E$ molecules recognized by the antisera show the same solubility profile. The $\mathrm{E}$ activities detected in gelatin- 


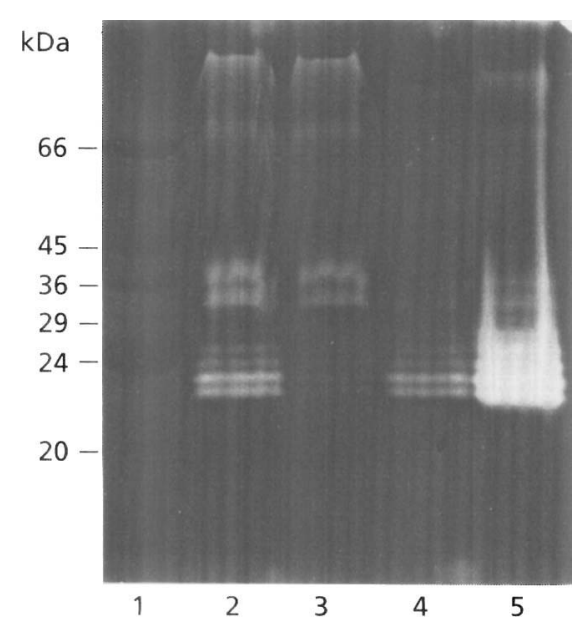

Fig. 5. Gelatin-SDS-PAGE analysis of L. mexicana amastigote freeze-thaw lysate pellet and supernatant fractions. $L$. mexicana amastigotes were lysed by six cycles of freezing and thawing. Samples of the pellet fraction $(11600 \mathrm{~g}, 5 \mathrm{~min}$; lane 2), washed pellet (lane 3), pellet-wash supernatant fraction (lane 4) and lysate supernatant fraction (lane 5) were analysed for protease activity in a gelatin-SDS-PAGE gel. Molecular mass markers were run in lane 1 . The two activity bands around $36 \mathrm{kDa}$ in lanes 2 and 3 are the group E CP enzymes.

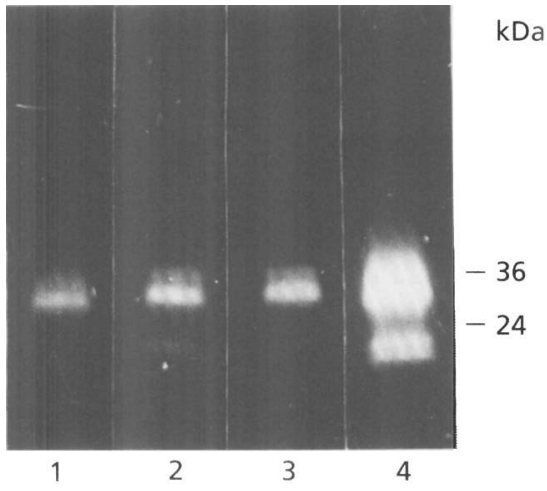

Fig. 6. Activity of L. mexicana group E CPs towards peptidylamidomethyl coumarin substrates. Samples of $L$. mexicana amastigote lysate pellet fraction were separated by SDS-PAGE, and individual lanes were incubated with BzFVR-AMC (lane 1), SuCAFK-AMC (lane 2), LVY-AMC (lane 3) and PFR-AMC (lane 4). Note that the sample still has some groups $B$ and $C C P$ activity associated with it (faster-mobility bands in lanes 2,3 and, especially, 4).

SDS-PAGE gels were inhibited by a range of inhibitors, including the class-specific E-64, that indicates the enzymes to be CPs. Additionally, they hydrolyse the same fluorogenic substrates as the groups B and C CPs (Fig. 6). Their substrate preference and cross-reactivity with antisera recognizing the groups $A, B$ and $C$ CPs suggests that the E CPs could be related to these enzymes, and so could also be encoded within the $\operatorname{lmc} p b$ gene array. Group $\mathrm{E}$ CPs could not be detected in lysates of promastigote populations of $L$. mexicana.

\section{CPs of other Leishmania species}

Lysates of $L$. donovani and $L$. major exponential- and stationary-phase promastigote populations were also analysed on Western blots with the anti-C CP anti-serum (not shown). Molecules of around $30 \mathrm{kDa}$ were specifically recognized in these samples, and suggest the presence of CP activities similar to the $l m c p b$ products in these other two Leishmania species, although none were detected previously using gelatin-SDS-PAGE gels (Lockwood et al., 1987).

\section{DISCUSSION}

The prime aim of this study was to provide more information on the multiple $L$. mexicana amastigote CP activities detected in gelatin-SDS-PAGE gels. The Nterminal sequence data obtained in this study for the purified CP groups suggest that the CPs of groups $A, B$ and $C$ are very closely related and do not differ in the same way as barley aleurone layer CPs (Koehler \& Ho, 1988). The group C CP preparation that was sequenced gave two overlapping sequences, indicating that at least part of the reason for the heterogeneity of the two group C CPs is due to differential processing at the $\mathrm{N}$-terminus. The additional amino acid at the $\mathrm{N}$-terminus of the protein (alanine) is that predicted from the $\operatorname{lmcpb}$ gene.

The N-terminal amino acid sequence determined for all the CP proteins in this study closely matches that predicted for the N-terminus of the mature $\operatorname{lm} c p b$ gene product (Souza et al., 1992). This gene forms a tandem array of over ten copies, and its transcript is found at much higher levels in amastigotes than in metacyclic promastigote populations, and not at all in multiplicative promastigote populations. This mirrors the expression of the groups A, $B$ and C CP activities and proteins in these parasite populations (Lockwood et al., 1987; Robertson \& Coombs, 1992; Fig. 3). Recently, an lmcpb homologue, lpcys 2 , has been isolated and sequenced from L. pifanoi (Traub-Cseko et al., 1993). It too forms a tandem array of 8-20 copies, and has higher transcript levels in amastigotes than promastigotes. These tandem arrays of CP genes seem to lack restriction fragment length polymorphisms, suggesting that the gene copies are very similar (Souza et al., 1992).

The data presented here suggest that the sizes of the CP proteins of all three groups, A, B and C, are very similar, as the individual proteins of groups $B$ and $C$ run as single bands of $24 \mathrm{kDa}$ mobility in denaturing SDS-PAGE gels (Fig. 1), and the deglycosylated form of the group A CPs is apparently the same size as the groups $\mathrm{B}$ and $\mathrm{C}$ CP proteins (Fig. 4). The predicted molecular mass of the protein encoded by the central region of the $\operatorname{lmcpb}$ gene is $23578 \mathrm{Da}$. This suggests that the groups $\mathrm{A}, \mathrm{B}$ and $\mathrm{C}$ CPs are encoded almost entirely by this part of the gene. The lmcpb gene predicts a CP with a long C-terminal extension, as has been reported for a group of CPs in other trypanosomatids and some plants (North et al., 1990; Watanabe et al., 1991). The data presented here suggest that this C-terminal extension is cleaved from the central domain and not present in the mature CP protein. A 
Trypanosoma brucei rbodesiense CP has been heterologously expressed in Escherichia coli without its C-terminal extension, yet it remains enzymically active (Pamer et al., 1991). Thus, the C-terminal extension of this class of trypanosomatid CPs does not appear essential for activity and may have some other function.

The groups B and C CPs show some different preferences for peptidyl fluorogenic substrates after SDS-PAGE (Robertson \& Coombs, 1990), yet their protein sizes are the same (Fig. 1), they react with the same anti-sera (Fig. 4 ), and have closely similar N-terminal amino acid sequences (Fig. 2). Thus, the substrate-preference differences would appear to be due to small differences in the protein structures. Indeed, glycine or lysine is found at residue 11 in the different CP proteins sequenced (Fig. 2). Site-directed mutagenesis of the gene for the papaya $C P$, papain has altered the engineered enzyme's preference for peptide substrates away from that of papain towards that of the mammalian CP cathepsin B (Khouri et al., 1991). This was done simply by substituting two amino acid residues (Val133Ala/Ser205Glu) in the papain $\mathrm{S}_{2}$ binding pocket. It is therefore possible that limited amino acid substitutions in the different $l m c p b$ products will produce CPs with different substrate preferences. This implies that a number of different $l m c p b$ genes exist which account for the multiple CP activities, and hence that comparison of their sequences with the properties of the expressed enzymes would yield interesting insights into the molecular basis of these leishmanial CP substrate-binding specificities.

Further support for the idea that the groups A, B and C CPs are closely related comes from the studies using antisera raised separately against the groups B and C CPs. Both antisera recognized the groups $A, B$ and $C$ CP proteins in Western blots, indicating that they have shared epitopes (Fig. 4). Consistent with their high activity in amastigotes, the groups $\mathrm{B}$ and $\mathrm{C} \mathrm{CP}$ proteins produce the largest signal in Western blots of amastigote lysates. The same molecule is recognized in stationary-phase promastigote lysates, in which group B and C CP activities have been found along with the metacyclic promastigotespecific group F CPs that have a faster mobility in gelatinSDS-PAGE gels (Robertson \& Coombs, 1992). The peptide substrate preference of the group $F$ CPs is in general similar to that of the groups $\mathrm{A}, \mathrm{B}$ and $\mathrm{C} \mathrm{CPs}$, so the specific recognition, only in Western blots of stationary-phase promastigotes, of a molecule with faster mobility than the groups $\mathrm{B}$ and $\mathrm{C} \mathrm{CP}$ proteins suggests that the group F CPs could be related to the $\operatorname{lm} c p b$ products.

Two other molecules specifically recognized by the anti-C $\mathrm{CP}$ antiserum in Western blots of amastigote lysates also appear to be CP activities, and we have designated them group E (Figs 4 and 5). These activities remain with the pellet fraction after centrifugation of a crude amastigote lysate. Their inhibitor sensitivity indicates that they are CPs, and their substrate preference towards test peptide substrates is similar to that of the groups A, B and C CPs (Fig. 6). The E CP activities can be released from the pellet fraction by $0 \cdot 1 \%$ SDS (as in SDS-PAGE sample buffer), high ionic strength $(2 \mathrm{M} \mathrm{NaCl})$ and high $\mathrm{pH}$ (above $\mathrm{pH} 9 \cdot 5$ ). This suggests that they are peripheral membrane proteins that act ionically with a membrane (Singer \& Nicolson, 1972; Fujiki et al., 1982). In T. cruzi, a proportion of the total cellular cruzipain has been reported to be surface-associated (Hellman et al., 1991), so the group E CPs may represent the $L$. mexicana homologue of this activity. Indeed, there is also a preliminary report of a plasma-membrane-associated CP activity in L. amazonensis amastigotes recognized by a specific monoclonal antibody (Vannier-Santos et al., 1991). However, a related $40 \mathrm{kDa}$ protein was not detected in this location using the same methodology. Other membrane-associated CPs have been reported, such as membrane-associated forms of the mammalian CPs, cathepsin L and cathepsin B, in certain metastasized cells (Rozhin et al., 1989; Sloane et al., 1986).

The two molecules in the pellet fraction of amastigote lysates that are recognized by the anti-C CP anti-serum are solubilized by the same procedures as the $\mathrm{E} \mathrm{CP}$ activities. These results suggest that the E CP activities could also be products of $l m c p b$ genes. How can their higher apparent molecular mass in SDS-PAGE gels be explained? They are not apparently $N$-glycosylated, so it seems unlikely that their high molecular mass and pellet association is due to highly glycosylated forms binding with membranebound mannose 6-phosphate receptors. Phosphorylated mannose residues were not found in the related protozoon, T. cruzi (Cazzulo et al., 1990), and the release of the $\mathrm{E} C P \mathrm{~s}$ from the pellet fraction at $\mathrm{pH} 9.5$ also argues against this possibility, as mannose 6-phosphate receptors usually release their ligands at low $\mathrm{pH}$ (Gonzalez-Noriega et al., 1980). The apparent molecular masses of the two molecules recognized by the anti-C CP antiserum in Western blots of E CP samples are $36 \cdot 3$ and $32.5 \mathrm{kDa}$ (Fig. 4). Their relatively large size could be due to their being less processed gene products. The predicted molecular mass of pro-Lmcpb lacking the C-terminal extension is $35863 \mathrm{Da}$, whereas the predicted molecular mass of the Lmcpb central domain plus C-terminal extension is 34071 Da (Souza et al., 1992; North et al., 1990). Retention by the E CPs of the predicted C-terminal extension could explain the location of the enzyme. There are a number of conserved cysteine residues in the CP C-terminal extensions described so far, suggesting a conserved and compact secondary structure in this domain (Souza et al., $1992)$; this may be involved in the enzymes' membraneassociation. An alternative possibility is that the Cterminal extension could be a signal for intracellular targeting. The C-terminal pro-peptide of barley lectin is involved in the protein's targeting to the plant vacuole (Bednarek \& Raikhel, 1991), and the short C-terminal extension of the T. brucei glycosomal phosphoglycerate kinase is necessary for targeting of this enzyme to the glycosome (Sommer et al., 1993).

Data have been presented that the pro-forms of the mammalian lysosomal proteases cathepsin $\mathrm{L}$ and cathepsin D are membrane-associated (McIntyre \& Erickson, 1991). Like the L. mexicana group E CPs, this association can be disrupted by high ionic strength or high $\mathrm{pH}$. The 
association is reversible, dependent on the pro-region of the protein, and is proposed to occur via a lysosomal protein receptor in microsomal membranes. Thus, proforms of lysosomal enzymes can be specifically translocated to the lysosome independently of the mannose 6phosphate receptor pathway. It is feasible that such a pathway is involved in the targeting of the $\operatorname{lm} c p b$ products to their subcellular location in the lysosome-like megasome (Pupkis et al., 1986), and that group E CPs represent such enzymes. Purification and N-terminal sequence analysis of the E CPs should indicate whether these proteins are pro-enzymes or mature enzymes with the retained $\mathrm{C}$-terminal extension.

The predicted molecular mass of the entire $l m c p b$ product is $47840 \mathrm{Da}$ (Souza et al., 1992), and molecules in this molecular mass range were specifically recognized by the anti-C CP anti-serum in Western blots of amastigote lysates (Fig. 3). This indicates that the whole of the $\operatorname{lm} c p b$ transcript is likely to be translated before being processed to the mature active enzymes. In addition, molecules in the molecular mass range $20-14 \mathrm{kDa}$ were also specifically recognized by the antiserum at higher loadings of amastigote lysate (Fig. 3, lane 3). These were probably proteolytic fragments of the mature CPs.

The findings that molecules of around $30 \mathrm{kDa}$ were specifically recognized by the anti-C CP antiserum in Western blots of $L$. donovani and $L$. major lysates, and that homologues of the L. pifanoi lpcys 2 gene (which is homologous with $\operatorname{lmcpb}$ ) have been detected in other leishmanias, albeit at lower levels (Traub-Cseko et al., 1993), suggest that $l m c p b$ homologues are common to all leishmanias, but that the enzymes occur at much greater levels in the $L$. mexicana sub-class.

Further delineation of the interrelationship of the multiple lmcpb products may best be probed using genetic manipulation, studies which are now under way. In particular, the expression of a single $\operatorname{lmc} p b$ copy in a $\operatorname{lmc} p b$ free background, followed by biochemical analysis of the expressed product, will allow individual $l m c p b$ copies to be matched to individual CP activities. Similarly, expression of engineered $l m c p b$ products lacking the Cterminal extension may give an insight into the role of this protein domain. The $\operatorname{lm} c p b$ genes and their products therefore provide an excellent system in which to study CP structure-function relationships and their roles in the parasite's life.

\section{ACKNOWLEDGEMENTS}

This project was supported by awards from the EEC and the Wellcome Trust. We thank John Laurie and David Laughland for provision of leishmania samples, and Bryan Dunbar for protein sequencing.

\section{REFERENCES}

Bednarek, S. Y. \& Raikhel, N. V. (1991). The barley lectin carboxyterminal propeptide is a vacuolar protein sorting determinant in plants. Plant Cell 3, 1195-1206.

Cazzulo, J. J., Hellman, U., Couso, R. \& Parodi, A. J. (1990). Amino acid and carbohydrate composition of a lysosomal cysteine proteinase from Trypanosoma cruzi. Absence of phosphorylated mannose residues. Mol Biocbem Parasitol 38, 41-48.

Coombs, G. H. (1982). Proteinases of Leishmania mexicana and other flagellate protozoa. Parasitology 84, 149-155.

Coombs, G. H., Robertson, C. D. \& Mottram, J. C. (1991). Cysteine proteinases of leishmanias. In Biocbemical Protozoology, pp. 208-220. Edited by G. H. Coombs \& M. J. North. London: Taylor \& Francis.

Fujiki, Y., Hubbard, A. L., Fowler, S. \& Lazarow, P. B. (1982). Isolation of intracellular membranes by means of sodium carbonate treatment: application to endoplasmic reticulum. J Cell Biol 93, 97-102.

Gonzalez-Noriega, A., Grubb, J. H., Talkad, V. \& Sly, W. S. (1980). Chloroquine inhibits lysosomal enzyme pinocytosis and enhances lysosomal enzyme secretion by impairing receptor recycling. $J$ Cell Biol 85, 839-852.

Harlow, E. \& Lane, D. (editors) (1988). In Antibodies: a Laboratory Manual. Cold Spring Harbor, NY: Cold Spring Harbor Laboratory.

Hellman, U., Wernstedt, C. \& Cazzulo, J. J. (1991). Self-proteolysis of the cysteine proteinase, cruzipain, from Trypanosoma cruzi gives a major fragment corresponding to its carboxy-terminal domain. Mol Biochem Parasitol 44, 15-22.

Khouri, H. E., Vernet, T., Menard, R., Parlati, F., Laflamme, P., Tessier, D. C., Gour-Salin, B., Thomas, D. Y. \& Storer, A. C. (1991). Engineering of papain: selective alteration of substrate specificity by site-directed mutagenesis. Biochemistry 30, 8929-8936.

Koehler, S. \& Ho, D. H. (1988). Purification and characterisation of gibberelic acid-induced cysteine endoproteases in barley aleurone layers. Plant Physiol 87, 95-103.

Lockwood, B. C., North, M. J., Mallinson, D. J. \& Coombs, G. H. (1987). Analysis of Leishmania proteinases reveals developmental changes in species-specific forms and a common $68-\mathrm{kDa}$ activity. FEMS Microbiol Lett 48, 345-350.

Mallinson, D. J. \& Coombs, G. H. (1986). Molecular characterisation of the metacyclic forms of Leishmania. IRCS Med Sci 14, 557-558.

Matsudaira, P. (1987). Sequence from picomole quantities of proteins electroblotted onto polyvinylidene difluoride membranes. $J$ Biol Chem 262, 10035-10038.

McIntyre, G. F. \& Erickson, A. H. (1991). Procathepsins $L$ and $D$ are membrane-bound in acidic microsomal vesicles. J Biol Chem 266, 15438-15445.

Mottram, J.C. \& Coombs, G. H. (1985). Leishmania mexicana: enzyme activities of amastigotes and promastigotes and their inhibition by antimonials and arsenicals. Exp Parasitol 59, 151-160.

Mottram, J. C., Robertson, C. D., Coombs, G. H. \& Barry, J. D. (1992). A developmentally-regulated cysteine proteinase gene of Leishmania mexicana. Mol Microbiol 6, 1925-1932.

North, M. J. \& Coombs, G. H. (1981). Proteinases of Leishmania mexicana amastigotes and promastigotes: analysis by gel electrophoresis. Mol Biochem Parasitol 3, 293-300.

North, M. J., Mottram, J. C. \& Coombs، G. H. (1990). Cysteine proteinases of parasitic protozoa. Parasitol Today 6, 270-275.

Pamer, E. G., Davis, C. E. \& So, N. (1991). Expression and deletion analysis of the Trypanosoma brucei rbodesiense cysteine protease in Escherichia coli. Infect Immun 59, 1074-1078.

Pupkis, M. F., Tetley, L. \& Coombs, G. H. (1986). Leishmania mexicana: amastigote hydrolases in unusual lysosomes. Exp Parasitol 62, 29-39.

Robertson, C. D. \& Coombs, G. H. (1990). Characterisation of three 
groups of cysteine proteinases in the amastigotes of Leishmania mexicana mexicana. Mol Biochem Parasitol 42, 269-276.

Robertson, C. D. \& Coombs, G. H. (1992). Stage-specific proteinases of Leishmania mexicana mexicana promastigotes. FEMS Microbiol Lett 94, 127-132.

Rozhin, J., Wade, R., Honn, K. V. \& Sloane, B. F. (1989). Membraneassociated cathepsin L: a role in metastasis of melanomas. Biochem Biophys Res Commun 164, 556-561.

Singer, S. J. \& Nicolson, G. L. (1972). The fluid mosaic model of structure of cell membranes. Science 175, 720-731.

Sloane, B. F., Rozhin, J., Johnson, K., Taylor, H., Crissman, J. D. \& Honn, K. V. (1986). Cathepsin B: association with plasma membrane in metastatic tumors. Proc Natl Acad Sci US A 83, 2483-2487.

Sommer, J. M., Peterson, G., Keller, G.-A., Parsons, M. \& Wang,

C. C. (1993). The C-terminal tripeptide of phosphoglycerate kinase is both necessary and sufficient for import to the glycosomes of Trypanosoma brucei. FEBS Lett 316, 53-58.

Souza, A. E., Waugh, S., Coombs, G. H. \& Mottram, J. C. (1992).
Characterization of a multi-copy gene for a major stage-specific cysteine proteinase of Leishmania mexicana. FEBS Lett 311, 124-127.

Traub-Cseko, Y. M., Duboise, M., Boukai, L. K. \& McMahon-Pratt, D. (1993). Identification of two distinct cysteine proteinase genes of Leishmania pifanoi axenic amastigotes using the polymerase chain reaction. Mol Biochem Parasitol 57, 101-116.

Vannier-Santos, M. A., Doboise, S. M., Pan, A., McMahon-Pratt, D. \& De Souza, W. (1991). Immunocytochemical localization of cysteine proteinase in amastigotes of Leishmania amazonensis. Mem Inst Oswaldo Cruz 86, supl. 1, 131.

Watanabe, H., Abe, K., Emori, Y., Hosoyama, H. \& Arai, S. (1991). Molecular cloning and gibberellin-induced expresion of multiple cysteine proteinases of rice seeds (oryzains). J Biol Chem 266, 16897-16902.

Received 10 May 1993; revised 31 August 1993; accepted 21 September 1993. 